\title{
SIMULATION AND EXPERIMENTAL EVALUATION OF AN INNOVATIVE ROTARY COMPRESSOR WITH VARIABLE SPEED DISPLACERS
}

\author{
H. J. Kopelowicz, \\ A. R. Barreto ${ }^{b}$, \\ F. L. C. Moutellab, \\ H. T. Arêas ${ }^{\text {, }}$ \\ C. E. R. Siqueirac, \\ and J. A. R. Parise ${ }^{b}$ \\ ${ }^{a}$ Dalvic Comércio e Indústria Ltda. \\ 20220-330, Rio de Janeiro, RJ, Brazil \\ ${ }^{b}$ Pontifícia Universidade Católica do Rio de \\ Janeiro \\ Departamento de Engenharia Mecânica \\ 22453-900, Rio de Janeiro, RJ, Brazil \\ parise@puc-rio.br \\ ${ }^{\mathrm{c}}$ Universidade Católica de Petrópolis \\ Departmento de Engenharia Mecânica \\ 25600-000, Petrópolis, RJ, Brazil
}

\section{ABSTRACT}

This paper describes preliminary studies of a new rotary compressor with variable speed displacers. Two displacers rotate concentrically, in an annular space, at variable and phased angular velocities, thus creating two variable-volume compression spaces between them. The displacers are individually driven by two concentric shafts. An innovative driving mechanism imposes phased variable angular speeds to the shafts and, consequently, to the displacers, thus providing a volume variation in the gas compression spaces. The driving mechanism also offers a convenient way of capacity control, from zero to $100 \%$, at constant electric motor speed. A mathematical model simulating the performance was developed. A traditional simulation model for positive displacement compressors was employed, where mass and energy conservation equations, in differential form, were applied to the control volumes (two compression spaces). Uniformly distributed thermodynamic properties of gas, varying with time, were assumed for each control volume. Equations describing the volume variation with time, the gas to cylinder wall heat transfer and gas flow through valve ports and leakage passages were also employed. The resulting mathematical model was a system of ordinary differential equations, the numerical integration of which provides the time-history of pressure and temperature of the gas inside the compression chambers. A prototype was also constructed and tested. First performance results are presented, showing the compressor behaviour under different operational conditions.

Keywords: rotary compressor, simulation, capacity control

\section{NOMENCLATURE}

$a \quad$ exponent in Eq. (11)

$A$ area, $\mathrm{m}^{2}$

$b \quad$ exponent in Eq. (11)

$c_{p} \quad$ specific heat at constant pressure, $\mathrm{J} / \mathrm{kgK}$

$c_{v} \quad$ specific heat at constant volume, $\mathrm{J} / \mathrm{kgK}$

$C \quad$ constant in in Eq. (11)

$C_{d} \quad$ discharge coefficient, dimensionless

$D_{e} \quad$ displacer external diameter, $\mathrm{m}$

$D_{i} \quad$ displacer internal diameter, $\mathrm{m}$

E energy, J

$h$ heat transfer coefficient, $\mathrm{W} / \mathrm{m}^{2} \mathrm{~K}$

$i \quad$ specific enthalpy, $\mathrm{J} / \mathrm{kg}$

$l \quad$ characteristic length, $\mathrm{m}$

$k \quad$ specific heat ratio, dimensionless

$L \quad$ displacer width, $\mathrm{m}$

$m$ mass, $\mathrm{kg}$

$\dot{m}$ mass flow rate, $\mathrm{kg} / \mathrm{s}$

$\mathrm{Nu} \quad$ Nusselt number, dimensionless

$P$ pressure, $\mathrm{Pa}$

$P r \quad$ Prandtl number, dimensionless

$R$ gas constant, $\mathrm{J} / \mathrm{kgK}$

$r \quad$ eccentricity ratio, dimensionless

Re Reynolds number, dimensionless

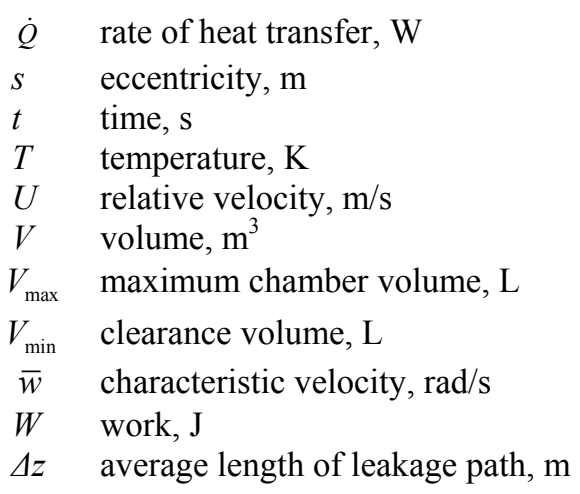

\section{Greek symbols}

$\begin{array}{ll}\alpha & \text { angular position of displacer } \mathrm{A}, \mathrm{rad} \\ \dot{\alpha} & \text { angular velocity of displacer } \mathrm{A}, \mathrm{rad} / \mathrm{s} \\ \beta & \text { angular position of displacer } \mathrm{B}, \mathrm{rad} \\ \dot{\beta} & \text { angular velocity of displacer } \mathrm{B}, \mathrm{rad} / \mathrm{s} \\ \delta & \text { gap, } \mathrm{m} \\ \gamma & \text { angular clearance, } \mathrm{rad} \\ \gamma_{0} & \text { displacer angle, } \mathrm{rad} \\ \theta & \text { driving shaft angle, } \mathrm{rad} \\ \dot{\theta} & \text { driving shaft angular velocity, } \mathrm{rad} / \mathrm{s}\end{array}$


$\lambda$ thermal conductivity, $\mathrm{W} / \mathrm{mK}$

$\mu \quad$ viscosity, $\mathrm{kg} / \mathrm{m} . \mathrm{s}$

$v$ kinematic viscosity, $\mathrm{m}^{2} / \mathrm{s}$

$\rho$ density, $\mathrm{kg} / \mathrm{m}^{3}$

$\zeta \quad$ leakage path average width, $\mathrm{m}$

\section{Subscripts}

\section{1 upstream}

2 downstream

I relative to control volume I

II relative to control volume II

$j \quad \mathrm{j}^{\text {th }}$ flow passage across the control volume

$l \quad$ leakage

$q \quad$ heat transfer

$v$ valve

w wall

\section{INTRODUCTION}

Recent advances in the development programme of an innovative rotary compressor (Kopelowicz, 2003) are presented in this paper. Rotary compressors are, of course, positive displacement machines where the traditional piston-slider crank mechanism of the reciprocating compressor is substituted by some sort of arrangement where the displacer (the piston in reciprocating compressors) presents a predominantly rotating movement. For this reason, rotary compressors are less subjected to mechanical vibration and, owing to potentially higher velocities, are usually smaller than their reciprocating counterpart, for a given volumetric capacity. Different types of rotary compressors are now available, including the sliding vane, stationary-vane rolling piston, scroll and screw compressors, all of which have found commercial application in many different fields. Innovative rotary compressors have long been reported in the literature, showing different stages of development and success (see, for example, Weinbrecht, 1990; Smith et al., 1992; Masuda et al., 1996; Sawai et al., 2000; Okuda et al., 2000; Ooi, 2003; and Lee et al., 2004).

This paper presents a preliminary evaluation of a new rotary positive displacement compressor. The Kopelrot Compressor Programme started with the construction of a demonstration scale model, to provide the first clues to the proposed compression device with its driving mechanism. A first proof-ofconcept prototype was then constructed to evaluate, at relatively low speeds, the behaviour of the volume variation mechanism. Since no similar machine had yet been constructed, a simulation model became an essential tool to establish basic geometric relations for the design and construction of a new prototype. A mathematical model simulating the performance of the new rotary compressor was then developed and is presented in this paper. A traditional angle-by-angle simulation method for positive displacement compressors (Soedel, 1972) was employed, based on mass and energy conservation equations, in differential form, applied to the control volumes (two compression spaces). A few important lessons were learned from the simulation effort. Given proper geometric relations, the proposed compressor showed to be able to function properly, with pressure-volume diagrams typical of traditional positive displacement compressors. Furthermore, the driving mechanism proved to be well suited for capacity control. This capability was further explored in the preliminary tests of the second prototype, the results of which are also reported in this paper.

\section{COMPRESSOR DESCRIPTION}

Figure 1 depicts the schematics of the proposed compressor. Two displacers rotate concentrically, in an annular space, at variable and phased angular velocities, thus creating two variable-volume compression spaces between them. Each displacer is attached to its own rotor.

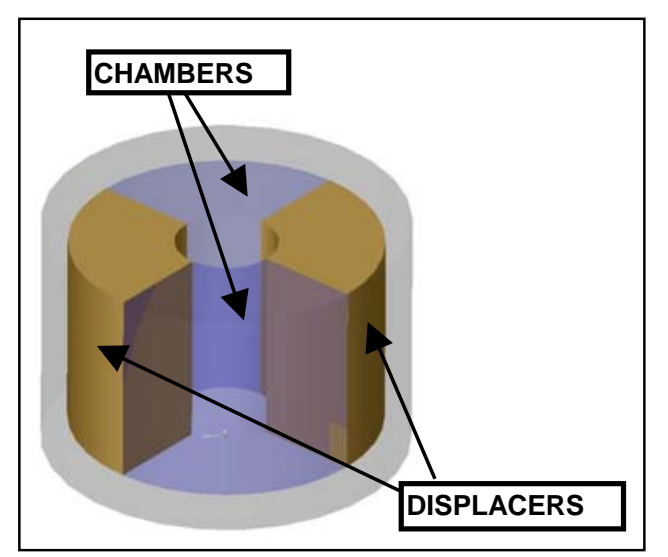

Figure 1. Schematics of the Kopelrot compressor.

The movement of the rotor/displacer assemblies is dictated by fixed-length cranks pivoted to a common slot of a driving disk, Figure 2, driven, by its turn, by a constant speed electric motor.

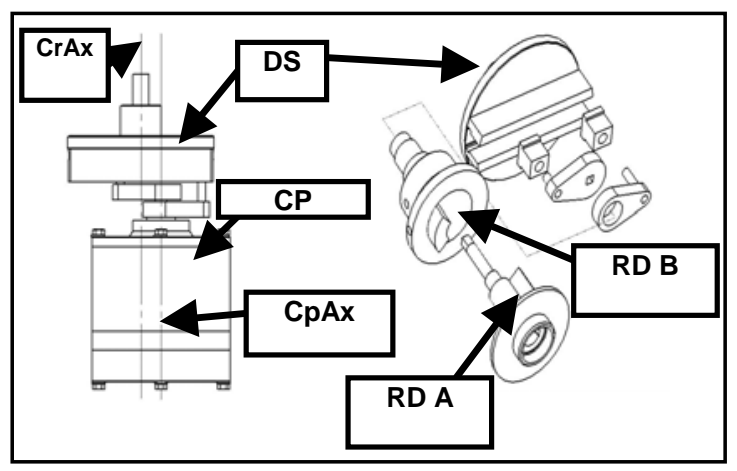

Figure 2. Overall and exploded view of the proposed compressor with its driving mechanism. CrAx: crank axis; DS: driving system; CP: compressor; CpAx: compressor axis; Rotor displacer A; Rotor displacer B. 
The pivoting point of each displacer is allowed to slide along the driving disk slot, as shown in Figure 2.

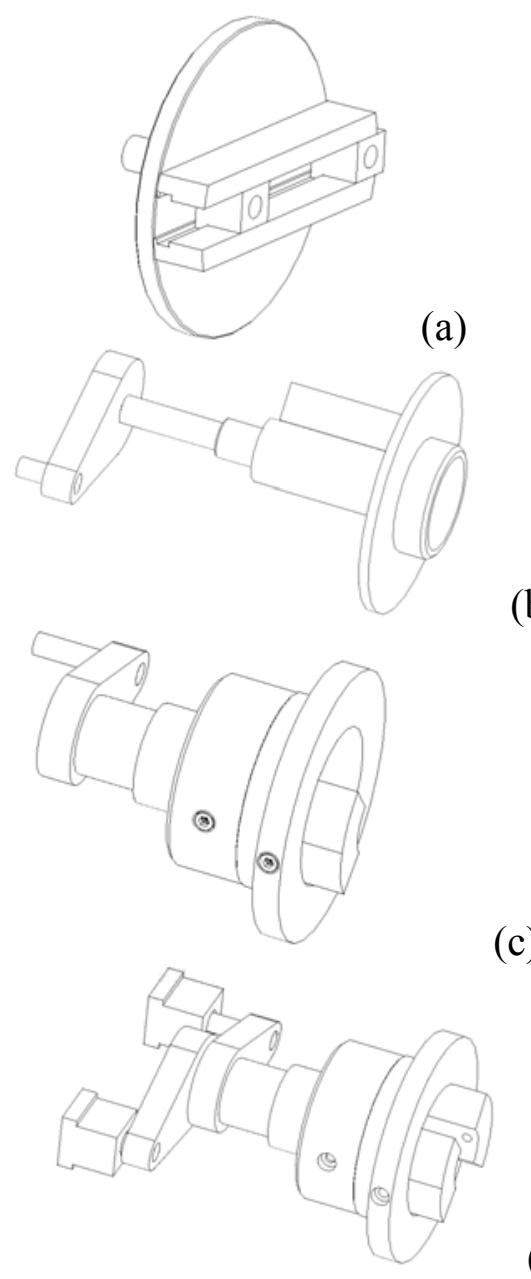

(b)

Figure 3. Views of: (a) Driving disk; (b) Rotor A assembly (with displacer, shaft and crank); (c) Rotor

B assembly; (d) Rotors A and B assembled.

Figures $3 \mathrm{a}$ to $3 \mathrm{~d}$ depict rotors $\mathrm{A}$ and $\mathrm{B}$, the driving disk and the rotors assembly, providing a close view of the driving mechanism. Note that rotors and disk are eccentrically mounted (see Figure 2). The resulting movement of the displacers and their respective sliding pivot points (guides) is depicted in Figures $4 \mathrm{a}$ and $4 \mathrm{~b}$, showing displacer and guide positions at each 45-degree of the driving axis. The locations of the suction and discharge ports are also shown in Figure 4a.

In spite of the guides (pivoting points) translational and rotational movements, the cranks are limited to rotate about the compressor axis. The angular velocity of the cranks, and their respective rotor/displacer assemblies, is determined by the position of their pivoting points. If a guide is in the centre of the disk, it will rotate around its own axis and will not rotate the crank. When it moves along the slot, it gains translational movement, which is converted to pure rotational movement of the cranks. The angular velocity increases when the guide moves farther away from the disk centre and decreases when otherwise. This innovative mechanism, patented by Kopelowicz [1], thus provides the required variable and phased angular velocity of the displacers. Inspection of Figure $4 \mathrm{a}$ shows that this is a positive displacement double-acting rotary compressor, with two full compression cycles per revolution of the driving axis.
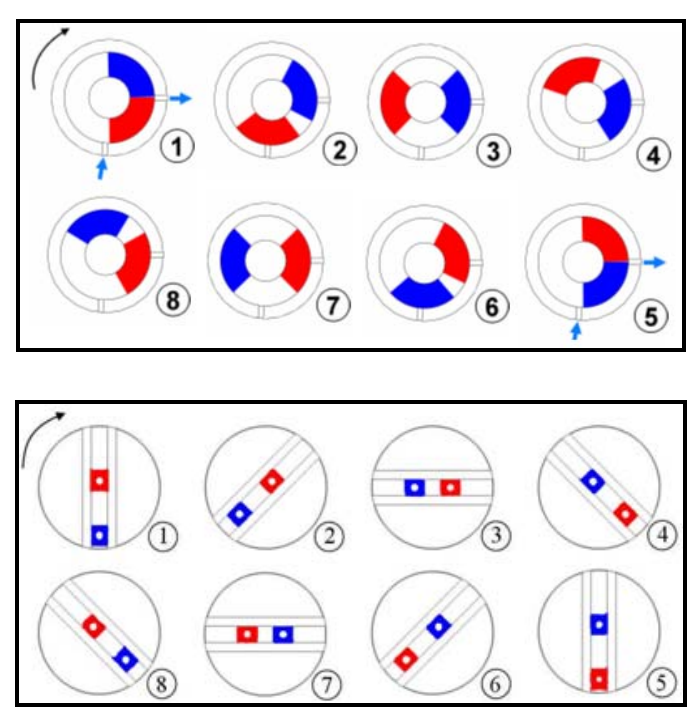

Figure 4. Principle of operation of the Kopelrot compressor: a) displacers positioning at every 45 degrees for one full shaft revolution; $b$ ) corresponding positions of levers' pivoting points.

Suction and discharge ports, eventually with valves, must be strategically located at the circumference of the cylinder, in the valve plate (see Figure 5). Note that the displacers perform a circumferential trajectory, with centre in the cylinder axis, thus avoiding direct contact between the moving parts and the cylinder surface (as in rotary vane and rolling piston compressors). This would dispense, in theory, the use of sealing parts, moreover, as most of the leakage paths are relatively long.

The amplitude of the angular speed variation of the displacers is dictated by the eccentricity of the device, i.e., the distance between compressor and electric motor axes. If the compressor axis is aligned with the driving plate axis, the distance from the crank guides to the disk centre will be equal, thus imposing equal velocities to their displacers and producing no compression. The displacers will rotate at constant speed, separated by a constant angle of 90 degrees. When an eccentricity is imposed, that distance will vary, resulting in a 180-degree phased movement and chamber's volume variation. The eccentricity can be mechanically adjusted, allowing unique soft start-ups, with no compression and progressive increase of speed up to the required 
operating conditions. Soft start-ups contribute to extend equipment life and reduce maintenance costs. Also, capacity control systems could be implemented to modulate the compressor volumetric capacity, reducing energy consumption when lower capacity is required and maintaining continuous operation.

Figure 5 shows a sectioned view of the compressor fully assembled. Basic components are: rotors $\mathrm{A}$ and $\mathrm{B}$, encompassing respective shafts, displacers A and B, firmly attached to their corresponding rotors, shell, top and lower covers, and the valve "plate", in fact a $10 \mathrm{~mm}$-thick hollow disk where suction and discharge gas passages are drilled radially and valves are eventually installed. The discharge valve has to be positioned in the inner surface of the valve plate, so as to avoid an excessive clearance volume. To be noted the concentric movement of both displacers, leading to an operation with lower vibration levels. Internal and external gas leakage can be diminished with proper manufacturing tolerances or with the use of seals.

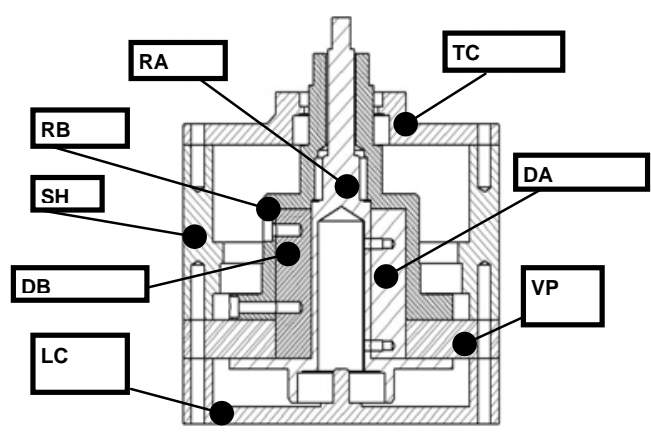

Figure 5. Sectioned view of the compressor (fully assembled; driving mechanism not shown). RA: rotor

A; RB: rotor B; SH: shell; DA: displacer A; DB:

displacer B; LC: lower cover; TC: top cover; VP: valve plate.

\section{MATHEMATICAL MODEL}

The traditional transient method (angle-byangle) of simulating positive displacement compressors (Soedel, 1972; Ignatiev, 2000) was employed for compression of air. Two control volumes were established, comprising each one of the compression spaces (Figure 1). Mass and energy conservation equations were applied assuming uniformly distributed gas properties in the control volume.

$$
\begin{gathered}
\frac{d m}{d t}=\sum_{j} \dot{m}_{j} \\
\frac{d E}{d t}=\dot{Q}-\frac{\delta W}{\delta t}+\sum_{j} \dot{m}_{j} i_{j}
\end{gathered}
$$

Assuming perfect gas and negligible variation of the kinectic and potential energies, and combining
Eqs. (1) and (2), the time-derivative of the gas temperature in the compression chamber is given by:

$$
\begin{aligned}
& \frac{d T}{d t}=-\frac{1}{m c_{v}} \times \\
& \left\{-\dot{Q}+\sum_{j}\left[\dot{m}_{j} c_{p}\left(T-T_{j}\right)\right]+P \frac{d V}{d t}-R T \sum_{j} \dot{m}_{j}\right\}
\end{aligned}
$$

\section{Equations of Motion: Displacer Position and Angular Velocity}

Figure 6 shows the basic geometric parameters of the compressor, with displacers and drive mechanism. Taking both levers horizontally opposed as the starting position $(\alpha=\beta=\theta=0$, Figure 4, frame [3]), the angular position of displacers B and A (phased by $180^{\circ}$ ) are given by, respectively:

$$
\begin{aligned}
& \beta=\theta-\arcsin \left(\frac{s}{l} \sin \theta\right)=\theta-\arcsin (r \sin \theta) \\
& \alpha=2 \theta-\beta
\end{aligned}
$$
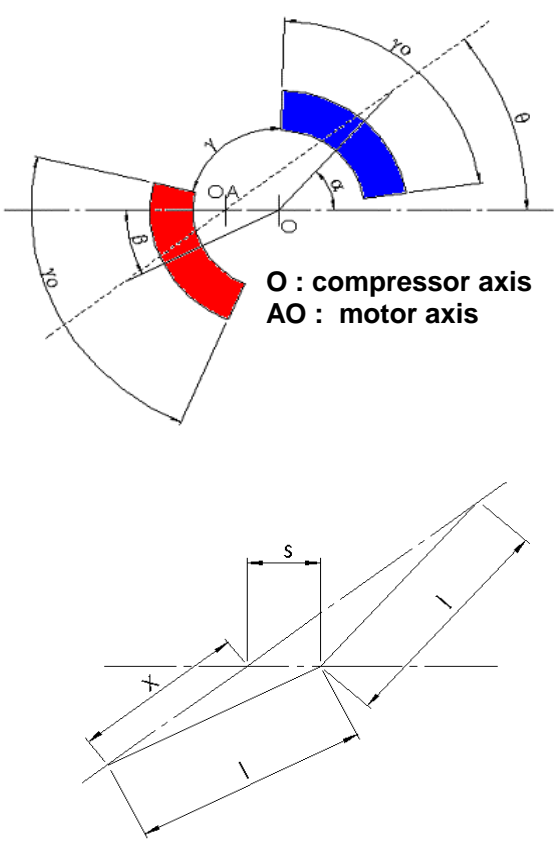

Figure 6. Geometric parameters of the displacers and driving mechanism.

The chamber angular clearance, i.e., the angular distance between the two displacers, is:

$$
\gamma=\beta+\pi-\alpha-\gamma_{0}
$$

The time derivative of Eqs. (4) provides the instantaneous angular velocity of both displacers, as a function of the electric motor constant angular velocity, $\dot{\theta}$. 


$$
\begin{aligned}
& \dot{\beta}=\dot{\theta}\left(1-\frac{(r \cos \theta)}{\sqrt{1-r^{2} \sin ^{2} \theta}}\right) \\
& \dot{\alpha}=2 \dot{\theta}-\dot{\beta}
\end{aligned}
$$

Note that the second term inside the parenthesis gives the variation of the angular velocity around the constant value of the driving shaft speed, $\dot{\theta}$, and the amplitude of this variation is a function of the eccentricity ratio, $r=(s / l)$.

\section{Volume Equation}

The rate of change of the control volume is obtained from the angular clearance, $\gamma$.

$$
\frac{d V}{d t}=\left(D_{e}^{2}-D_{i}^{2}\right) \frac{L}{8} \frac{d \gamma}{d t}
$$

\section{Heat Transfer Rate Equation}

Neglecting radiation, the heat exchange rate between the gas and control volume walls is given by:

$$
\dot{Q}=h A_{q}\left(T_{w}-T\right)
$$

where the total instantaneous heat exchange area, combining the six faces of the control volume, Figure 1, is:

$$
A_{q}=\frac{\left(D_{e}^{2}-D_{i}^{2}\right) \gamma}{4}+\left(D_{e}-D_{i}\right) L+\frac{L \gamma}{2}\left(D_{e}+D_{i}\right)
$$

The instantaneous heat transfer coefficient is adapted from a correlation originally developed for sliding-vane compressors (Gnutek e Kalinowski, 1996).

$$
\begin{aligned}
& h=\frac{N u \lambda}{l} \\
& N u=C(\operatorname{Re})^{a}(\operatorname{Pr})^{b} \\
& \operatorname{Re}=\frac{\bar{w} l}{v}
\end{aligned}
$$

Parameters $C, a$ and $b$ are, for laminar flow, $0.66,0.6$ and 0.33 , respectively, and $0.037,0.8$ and 0.43 , for turbulent flow. Transition is assumed to occur at $R e=10^{5}$. The Reynolds number characteristic length and velocity are defined as:

$$
\begin{gathered}
l=\frac{\gamma\left(D_{e}+D_{i}\right)}{4} \\
\bar{w}=\frac{|\dot{\beta}-\dot{\alpha}|\left(D_{e}+D_{i}\right)}{4}
\end{gathered}
$$

\section{Mass Flow Equations}

Mass flow across the control surfaces, $\dot{m}_{j}$, in Eqs. (1) and (2), occurs through valve passages and leakage paths. To obtain the valve mass flow rate equation, the compressor was modeled as having suction and discharge valves, both regarded as sharpedged orifices, operating at fully-open/fully-closed position. Sub-sonic quasi-steady flow and upstream stagnation conditions were assumed. Mass flow rate was calculated from the isentropic flow expression, e.g., from Parise and Cartwright (1985), corrected by a discharge coefficient (Deschamps et al., 1988).

$$
\dot{m}_{v}=C_{d} A_{v} \frac{P_{1}}{T_{1}^{1 / 2}}\left\{\frac{2 k}{R(k-1)}\left[\left(\frac{P_{2}}{P_{1}}\right)^{\frac{2}{k}}-\left(\frac{P_{2}}{P_{1}}\right)^{\frac{k+1}{k}}\right]\right\}^{1 / 2}
$$

The equation for the mass flow rate through leakage paths is obtaining by analysis of the relative movements between the displacers, rotors and valve plate. These parts require a clearance fit, so that leakage will occur between spaces (compression chambers, at pressures $P_{I}$ and $P_{I I}$, and shell space, at suction pressure). Gas leakage can occur from chamber to chamber (circumferential flow) and from chamber to shell space (radial and axial flow). Also, no leakage between rotors and their respective displacers is expected, due to adequate assembly sealing. Following experience with a prototype under construction, radial and axial leakage flows were neglected by the present model, due to the existence of appropriate seals.

As for circumferential flows, Figure 7 depicts possible leakage paths between compression chambers. To determine the tangential leakage, gas flow between parallel plates, one stationary and the other at a velocity $U$, is assumed, neglecting curvature effects and the presence of oil. Assuming constant pressure gradient, the leakage mass flow rate out of control volume $\mathrm{I}$ is given by (Fox and McDonald, 1998):

If $P_{I}-P_{I I}>0$

$$
\dot{m}_{l}=-\zeta\left[\frac{U \delta}{2}+\frac{1}{12 \mu}\left(\frac{P_{I}-P_{I I}}{\Delta z}\right) \delta^{3}\right] \rho
$$

$$
\text { If } \begin{aligned}
P_{I}-P_{I I} & <0: \\
\qquad \dot{m}_{l} & =\zeta\left[-\frac{U \delta}{2}+\frac{1}{12 \mu}\left(\frac{P_{I}-P_{I I}}{\Delta z}\right) \delta^{3}\right] \rho
\end{aligned}
$$




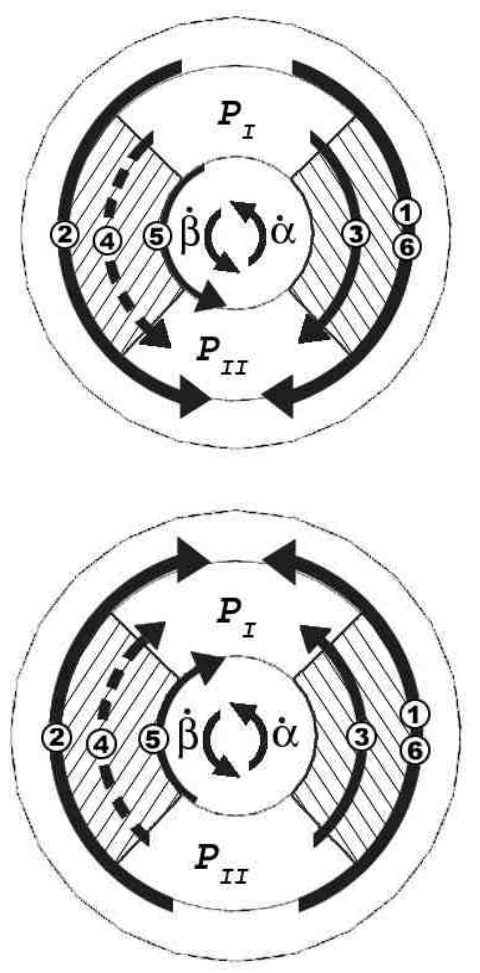

Figure 7. Possible leakage paths between compression spaces. a) $\left(\mathrm{P}_{\mathrm{I}}-\mathrm{P}_{\mathrm{II}}\right)>0$; b) $\left(\mathrm{P}_{\mathrm{I}}-\mathrm{P}_{\mathrm{II}}\right)<0$.

Two slightly different equations, (16) and (17), are necessary since both displacers rotate on the same direction but pressure difference between chambers, $\left(P_{I}-P_{I I}\right)$, oscillate between positive and negative. When the relative speed, $U$, is positive (direction from higher to lower pressure), it contributes to leakage flow and the opposite when negative. The parameters for Eqs. (16) and (17), for each leakage path, are given next.

1) Lateral leakage between the valve plate and displacer A:

$$
\begin{aligned}
& \zeta=L_{a} \\
& U=-\dot{\alpha} \frac{D_{e}}{2} \\
& \Delta z=\frac{\gamma_{o} D_{e}}{2}
\end{aligned}
$$

2) Lateral leakage between the valve plate and displacer B:

$$
\begin{aligned}
& \zeta=L_{a} \\
& U=-\dot{\beta} \frac{D_{e}}{2} \\
& \Delta z=\frac{\gamma_{o} D_{e}}{2}
\end{aligned}
$$

$$
\begin{aligned}
\zeta & =\frac{D_{e}-D_{i}}{2} \\
U & =-(\dot{\alpha}-\dot{\beta})\left(\frac{D_{e}+D_{i}}{4}\right) \\
\Delta z & =\frac{D_{e}+D_{i}}{4} \gamma_{o}
\end{aligned}
$$

4) Lower leakage between rotor A and displacer B:

$$
\begin{aligned}
& \zeta=\frac{D_{e}-D_{i}}{2} \\
& U=(\dot{\alpha}-\dot{\beta})\left(\frac{D_{e}+D_{i}}{4}\right) \\
& \Delta z=\frac{D_{e}+D_{i}}{4} \gamma_{o}
\end{aligned}
$$

5) Internal leakage between rotor A and displacer B:

$$
\begin{aligned}
& \zeta=L \\
& U=(\dot{\alpha}-\dot{\beta}) \frac{D_{i}}{2} \\
& \Delta z=\frac{\gamma_{o} D_{i}}{2}
\end{aligned}
$$

6) External leakage between rotor B and displacer A:

$$
\begin{aligned}
& \zeta=L-L_{a} \\
& U=-(\dot{\alpha}-\dot{\beta}) \frac{D_{e}}{2} \\
& \Delta z=\frac{\gamma_{o} D_{e}}{2}
\end{aligned}
$$

\section{SIMULATION}

\section{Capacity Control Capability}

Predicted results of volume variations for cylinder geometry of $100 \mathrm{~mm}, 88 \mathrm{~mm}$ and $38 \mathrm{~mm}$ of width, outer and inner diameters, respectively, revealed a relation between displaced and clearance (minimum) volumes with shaft eccentricity, as depicted in Figure 8. Clearly, as performance simulation results will confirm, further on, capacity control could be enforced, since both the displaced and clearance volumes are altered by the shaft eccentricity. For each geometry there is a maximum eccentricity, which corresponds to zero clearance volume (with displacers, theoretically, touching each other at one point of their trajectory). In practice, the compressor must operate below this value. The swept volume is, of course, the difference between the maximum and minimum volumes.

3) Top leakage between rotor B and displacer A: 


\section{Numerical Method}

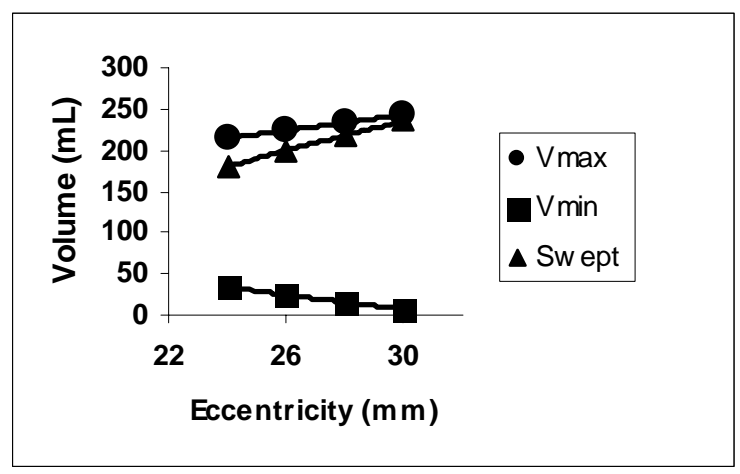

Figure 8. Variation of maximum, minimum and displaced volumes with shaft eccentricity.

Eqs. (4) to (23) are substituted into Eq. (3), to form, with Eq. (1), a system of non-linear ordinary differential equations. Integration was performed by the Euler method, with time increments of one crank angle degree. To guarantee numerical stability, this increment was further refined whenever suction or discharge valves were open. Starting from an arbitrarily established thermodynamic state, the 360degree compression cycle calculation was performed several times until convergence (pressure and temperature values at $\theta=0^{\circ}$ and $\theta=360^{\circ}$ ) was attained. Once one full cycle was performed, the pressure and temperature history of the chamber was phased by 180 degrees to describe the second chamber, thus allowing the leakage flow rates to be calculated.

\section{Results}

The model was applied to simulate the compressor with the following input data: suction pressure - $100 \mathrm{kPa}$; suction temperature - 324.15 K; discharge pressure - $1 \mathrm{MPa}$; driving shaft angular velocity - $2000 \mathrm{rpm}$; cylinder width $-0.06 \mathrm{~m}$; internal diameter $-0.038 \mathrm{~m}$; external diameter $0.088 \mathrm{~m}$; displacers angle $-90^{\circ}$; valve discharge coefficient -0.48 ; valve passage diameter $-0.015 \mathrm{~m}$; valve maximum displacement $-0.0015 \mathrm{~m}$; gap (overall) $-0.03 \mathrm{~mm}$. Figure 9 shows the predicted pressure-volume diagram for eccentricity ratios, ranging from 0.6 to 0.7 . One can observe the effect that the eccentricity has on both maximum and minimum volumes of the compression space, notably the latter. This means that the eccentricity ratio alters both displaced volume, $\left(V_{\max }-V_{\min }\right)$, and the clearance volume, $V_{\min }$, which constitute a reasonable possibility for capacity control. Theoretically, from geometrical considerations from Figure 4 , the clearance volume could be brought to zero, although manufacturing tolerances required some clearance to avoid displacer contact.

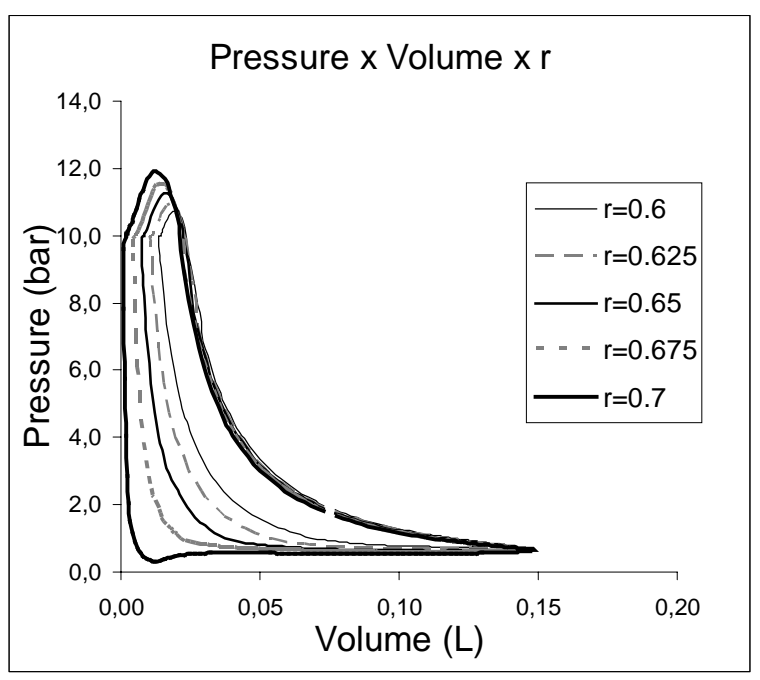

Figure 9. Pressure-Volume Diagram for different shaft eccentricity ratios.

\section{EXPERIMENTAL EVALUATION}

\section{Prototype and Experimental Apparatus}

Figure 10 shows two views of the prototype compressor in the test bench. Inner and outer diameters of the compression cylinder were $38 \mathrm{~mm}$ and $88 \mathrm{~mm}$, respectively. Length of the displacers, or cylinder width, was $100 \mathrm{~mm}$. The displacers were made of steel 1010, and the cylinder, of nodular iron. Due to large manufacturing tolerances and undesirable material expansion (in spite of forced liquid cooling on the cylinder external surface), mechanical seals (made of phosphorous bronze) were installed in this prototype. Figure 11 shows the rotor and displacers with respective seals (longitudinally- $a$, radially- $b$ and circumferentially- $c$ displaced). The compressor operated with a conventional discharge valve and a suction port (no valve), both strategically located alongside the valve plate circumference. As indicated by previous simulation results, the angular positions of the suction and discharge passages are key factors to the compressor performance. Modelling predictions also indicated that, should better manufacturing tolerances and cylinder cooling be applied, adequate performance could be achieved without the mechanical seals, as seen on figure 11 . The driving mechanism (crank pins, sliders and driving disc slot) was enclosed in a case containing oil, so as to provide "splash lubrication". Lubrication of the rotors and displacers was provided, on a provisional basis, by oil injection in the suction.

The compressor was driven by a variable speed electric motor, so as to have it tested over a range of shaft speeds. A wattmeter was employed, although a shaft torque meter is planned to be used in the future, to measure the compressor-only work, independently from the electric motor efficiency. A turbine flow 
meter was installed upstream the compressor, with two large volume tanks between them, in series, in order to minimise the amplitude and influence of air pulsation in the flow meter.
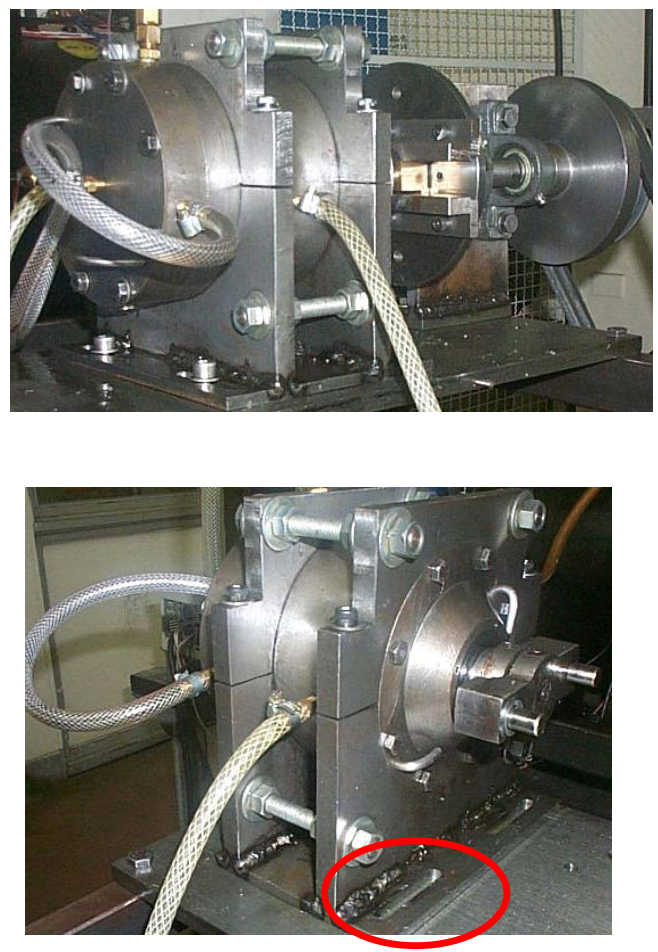

Figure 10. Prototype in the test bench.

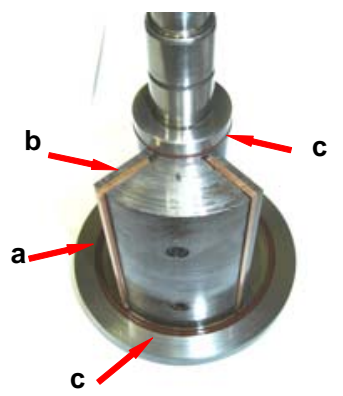

Figure 11. Rotor and displacer with mechanical seals.

Compressed air was pumped to a high-pressure 100L air reservoir. A pressure relief needle valve, installed in the reservoir, controlled the required air mass flow rate and, consequently, the discharge pressure. The maximum discharge pressure/no-flow condition (volumetric efficiency equal to zero) was achieved, for each combination of eccentricity and shaft speed, by operating the compressor against the air reservoir with the control valve fully closed. Temperature and pressure sensors were located at key points of the apparatus, to monitor the operation of the system.

\section{Results}

Tests were carried out for a shaft speed of 1130 $\mathrm{rpm}$. Figure 12 shows the normalized volumetric flow rate as a function of pressure ratio and shaft eccentricity. Three eccentricities to inner cylinder diameter ratios were evaluated, confirming the possibility of capacity modulation via adjustment of the shaft eccentricity. For example, for a pressure ratio of 3 , the volumetric flow rate could be reduced to approximately $30 \%$ of its original value with mere $4 \mathrm{~mm}$ of adjustment in compressor shaft positioning. Experimental observation showed that the effort to apply a new eccentricity value (i.e., to displace the compressor body along its base slots - see detail in figure 10) is small and compatible with existing (i.e., commercially available) linear displacement servomechanisms. In the prototype, eccentricity adjustments were made manually. In Figure 12, the full lines correspond to linear best fits for each group of eccentricity data points.

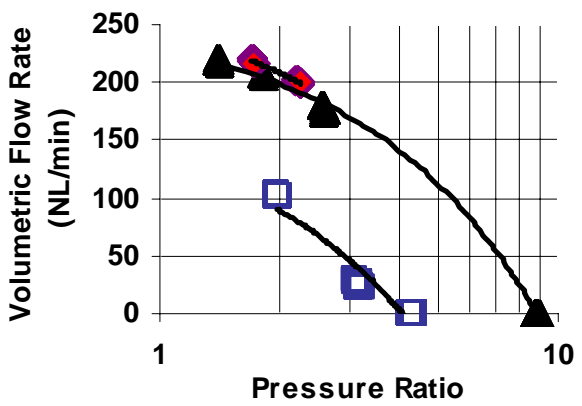

Figure 12. Compressor capacity versus pressure ratio, for three different eccentricity ratios $(0.55$, lower curve, 0.64 and 0.66 , respectively).

\section{CONCLUSIONS}

A new type of rotary compressor was proposed. Initial simulation results, obtained from a simplified model, demonstrated the technical feasibility of the proposed positive displacement device. A first prototype was constructed to evaluate, at relatively low speeds, the behavior of the volume variation mechanism. Since no previous reference was available for this compressor, the simulation model proved to be an important tool in the design stages of a second prototype, which was tested at normal operating conditions. Tests confirmed a major characteristic of the proposed conception, namely, the capacity control capability, via a simple adjustment of the eccentricity between shafts. This adjustment showed the possibility of capacity control during normal operation of the compressor.

\section{ACKNOWLEDGEMENTS}

Thanks are due to FAPERJ, FINEP and CNPq, Brazilian research funding agencies, which have 
financially supported this work. The authors are also indebted to Mr. Lucas B. Vancini for his invaluable services with the manufacturing of the prototype. The present work is based on two previous papers (Barreto et al., 2004; Kopelowicz et al., 2005).

\section{REFERENCES}

Barreto, A. R., Kopelowicz, H. J., and Parise, J. A. R., 2004, Simulation of an Innovative Rotary Compressor with Variable Speed Displacers, Proceedings of the 2004 International Compressor Engineering Conference at Purdue, vol. II, paper C128, pp. 1-8, West Lafayette, IN, USA, July 12-15.

Deschamps, C. J., Ferreira, R. T. S, and Prata, A. T., 1988, The Effective Flow and Force Areas in Compressor Valves, 1988 International Compressor Engineering Conference At Purdue, Purdue University, July 18-21, West Lafayette, USA.

Fox, R. W., McDonald, A. T., 1998, Introduction to Fluid Mechanics, John Wiley \& Sons.

Gnutek, Z., and Kalinowski, E., 1996, Heat Exchange in the Working Chamber of a Multi-vane Compressor, 1996 International Compressor Engineering Conference at Purdue, Purdue University, vol II, July 23-26, West Lafayette, USA.

Ignatiev, K., 2000, Compressor Modeling, USC/IIR Short Course "Simulation tools for vapor compression systems and component analysis", Purdue University, July 23-24, West Lafayette, USA.

Kopelowicz, H. J., 2003, A system for the construction of pumps, compressors and motor engines, formed by a rotary chamber and pistons which are driven in the same direction at varying velocities alternatively opposite to each other, inside a fixed open or closed structure, International Patent Application under PCT, International Publication Number WO 03/014549 A1, 20 February.

Kopelowicz, H. J., Siqueira, C. E. R., Moutella, F. L. C., Areas, H. T, and Parise, J. A. R., 2005, Experimental Evaluation of an Innovative Rotary Compressor with Variable Speed Displacers, International Conference on Compressors and their Systems, pp. 101-108, IMechE, London.

Lee, M., Cho, S., Sung, C., and Lee, S., 2004, Development of a variable capacity rotary compressor, Part I: Design concepts an evaluation experimental results, Proceedings of the 2004 International Compressor Engineering Conference at Purdue, vol. II, paper C113, pp. 1-5, West Lafayette, IN, USA, July 12-15.

Masuda, M., Sakitani, K., Yamamoto, Y., Uematsu, T., and Mutoh, A., 1996, Development of swing compressor for alternative refrigerants, Proc. 1996 International Compressor Engineering Conf. at Purdue, vol. II, pp. 499-504, West Lafayette, IN, USA.

Okuda, M., Fujiwara, T., and Hirayama, T., 2000, Development of a new mechanism compressor named "Helical, Proceedings of the $15^{\text {th }}$ Int.
Compressor Engineering Conf. at Purdue University, vol. II, pp. 1019-1025, West Lafayette, IN, USA.

Ooi, K. T., 2003, A study of a sliding cam compressor, International Conference on Compressor and their Systems, IMechE Conference Transactions, paper C615/073/2003, pp. 439-450, London, UK, 710 September.

Parise, J. A. R., Cartwright, W. G., 1985, Simulation of Reciprocating Compressors: Numerical Method and Comparison with Experimental Data, Revista Brasileira de Ciências Mecânicas, VII (2), pp. 129-152.

Sawai, K., Iida, N., Hasegawa, H., and Ishii, N., 2000, Dynamic analysis of new volumetric compressor with rotating cylinder and piston, Proc. $15^{\text {th }}$ Intnl. Compressor Engineering Conf. at Purdue University, vol. II, pp. 777-784, West Lafayette, IN, USA.

Smith, I. K., Harrison, H. R., and Cox, M., 1992, A preliminary evaluation of the Groll rotary vane compressor, Int. Jnl. of Refrigeration, vol. 15, no. 2, pp. 69-73.

Soedel, W., 1972, Introduction to Computer Simulation of Positive Displacement Type Compressors, 1972 Short Course Text, Ray W. Herrick Labs., School of Mechanical Engineering, Purdue University, West Lafayette, USA.

Weinbrecht, J. F., 1990, The flow work compressor, Proceedings of the 1990 Int. Compressor Engineering Conf. at Purdue, vol. II, pp. 557-566, USA, July 17-20. 